\title{
La reparación por incumplimiento contractual en el common law
}

\section{Remedies for breach of contract in the common law}

\author{
Julio Alberto Díaz*
}

\section{Resumen}

El sistema del common law, para los que no pertenecemos a él, representa sin dudas un mundo desconcertante e intrigante. El presente artículo probablemente sea un fiel reflejo de esa afirmación. La indemnización por incumplimiento contractual, una temática que ab initio pudiera imaginarse desprovista de toda complejidad, muestra en las páginas siguientes la falsedad de esta suposición. Algunos de esos aspectos, de la manera en que son concebidos en aquel sistema, son abordados de modo a ilustrar como, bajo el manto de la aparente simplicidad de la materia, innúmeras cuestiones de difícil solución suelen presentarse.

Palavras-chave: Contratos. Descumprimento contratual. Danos. Direito Comparado. Common Law.

\section{Abstract}

The common law, for those who do not belong to that system, represents, without any doubt, an intriguing and disconcerting world. The present article is probably a good reflex of that. Contractual damages, something that ab initio could be thought with no complexities at all, show in the next pages the falsity of that supposition. Some of those aspects, in the way they are conceived in that system, are approached so as to illustrate how, under the apparent simplicity of the subject, a large number of no easy questions to solve can and frequently arise.

Keywords: Contracts. Breach of contract. Damages. Comparative law. Common law.

Pós-Doutorado University of Ottawa, Canadá. Doutor em Direito Civil pela UFMG PhD in Law pela University of Canterbury New Zealand. Graduação em Direito pela Universidad Nacional de Córdoba, Argentina. Professor na Universidad Empresarial Siglo 21. Buenos Aires - Argentina. E-mail: julioalbertodiaz@windowslive.com 


\section{Introducción}

Podría afirmarse que el principio de que la indemnización por incumplimiento contractual tiene por objeto compensar al accionante por el daño sufrido se encuentra más allá de cualquier discusión, es decir, posee un carácter quase axiomático. En ese sentido, parecería banal, o al menos despojado de cualquier interés científico, la publicación de un artículo destinado a ahondar en una cuestión que inicialmente reconocemos podría pensarse ser de toda obviedad. Sin embargo, las páginas que siguen, utilizando como pretexto la enorme riqueza casuística del common law, habrán de demostrar lo contrario, es decir, que bajo el manto o la apariencia de una temática exenta de cualquier complejidad, subyacen innúmeras situaciones de no fácil solución.

\section{La compensación del daño contractual}

Tradicionalmente, se dice que indemnizar quiere decir "poner a uno, en tanto sea posible, en la misma situación patrimonial en que se encontraría, si no se hubiese producido el acontecimiento que obliga a la indemnización." (ENNECERUS, 1954, p. 62).

La compensación de los daños puede hacerse restableciendo efectivamente el estado que existiría de no haberse producido el acontecimiento causa del daño (reposición natural) o, de manera imperfecta, sólo con dinero a tenor del valor que esa prestación incumplida representa (prestación del interés pecuniario).

En los países del common law, a diferencia de los pertenecientes al sistema romanista, el principio tradicional es el de compensar al accionante por las pérdidas sufridas como resultado del incumplimiento, no el de forzar al contratante a cumplir su promesa. En ese sentido, en un famoso y controvertido pasaje, Holmes afirma que "una obligación contractual en el common law significa predecir que habrá que indemnizar si no se cumple. Nada más." 
En efecto, los tribunales vienen repitiendo desde 1848 un pasaje del Juez Parke en Robinson v Harman en que se afirma que "el objeto de la indemnización por incumplimiento contractual es poner al contratante, tanto cuanto el dinero lo permita, en la misma situación en que se encontraría si el contrato se hubiese cumplido." En otras palabras, el accionante tiene derecho a ser compensado por la pérdida del objeto de su contratación, de forma tal que la expectativa creada por el contrato resulte de ese modo protegida. (TREITEL, 2001, p. 873).

Esa protección de la expectativa es, en general, puesta en contraposición con el principio de la indemnización por daño extracontractual. En este caso, se dice, el propósito es simplemente el de colocar a la víctima en la misma posición en que ésta se encontraría si el acto ilícito no se hubiese producido. Dicho de otra manera, en la indemnización contractual se busca alcanzar lo que sería la situación post-cumplimiento, en la extracontractual, la situación pré-accidente. Evidentemente, que el tentar determinar en que posición alguien se encontraría si las cosas hubiesen sido diferentes será siempre puramente hipotético, sin embargo, esa es precisamente la cuestión que los tribunales se encuentran compelidos a resolver.

Naturalmente que en las acciones extracontractuales la víctima también puede resultar indemnizada por la pérdida de sus expectativas, como ocurre en el típico caso de lesiones físicas que provocan daños categorizados como de lucro cesante, pero en esos casos, esas expectativas, a diferencia de lo que ocurre con los contratos, ya existían independientemente del hecho causado por el demandado. La esencia del acto dañoso extracontractual es destruir expectativas y no crearlas como sucede en toda celebración convencional.

\section{Expectativa, confianza y restitución}

En el common law, la cuestión de la identificación del objeto de la reparación del daño contractual con la protección de la expectativa contractual generada por la contratación había permanecido de modo 
absolutamente pacífico por casi un siglo hasta que en 1936, la Revista Jurídica de la Universidad de Yale publica un artículo que, al menos en el ámbito académico (no así en el plano jurisprudencial, donde su influencia resultó limitada), habría de provocar un extraordinario movimiento intelectual en torno de la mencionada cuestión. En efecto, Lon L. Fuller ${ }^{1}$ en su célebre publicación intitulada "The reliance interest in contract damages." ('El interés de la confianza en la indemnización por incumplimiento contractual.') afirma que el principio que apunta a proteger la expectativa contractual es, en realidad, una extraña forma de compensación, ya que ella, con frecuencia, otorga al accionante algo que nunca tuvo, colocándolo en una mejor posición que la que tendría si el contrato no hubiese sido celebrado. En síntesis, la cuestión fundamental por él levantada se centra en la crítica al objeto de la indemnización por incumplimiento al proteger exclusivamente la expectativa contractual ya que en realidad, en muchos casos, todo lo que se debería garantizar, afirma, es simplemente, que el accionante no resulte en una peor situación de la que se encontraría si el contrato no hubiese sido celebrado.

En otras palabras, Fuller propone que lo que debe ser protegido también es lo que él denomina el interés de la confianza ${ }^{2}$ y no simplemente la expectativa contractual, o sea el interés en el cumplimiento.

Para eso, el celebrado profesor de Harvard afirma que la cuestión de la indemnización contractual no puede ser separada de la cuestión más amplia que es la de los fines de la ley en relación a los contratos en general, ni tampoco de las razones que subyacen en la obligatoriedad de los contratos. Manifiesta que es necesario establecer diferentes medidas de mensuración del daño de acuerdo con las diversas formas

El autor, poco tiempo después, alcanzó fama también en lengua castellana por su brillante opúsculo "El caso de los exploradores de cavernas".

2 Es llamativa la identidad terminológica con la existente en el derecho alemán, de quien Fuller seguramente la adoptó. No obstante, el llamado interés negativo o de la confianza en la doctrina germánica se refiere a los negocios jurídicos inválidos representando, por tanto, el daño que el acreedor ha experimentado en virtud de haber creído en la validez del negocio. 
de contratación e identifica tres situaciones diferentes en las que la ley procura, al conceder una particular indemnización que considera la más adecuada, un propósito diverso en cada una de ellas.

El primer caso se presenta cuando el accionante, basándose en la confianza despertada por la promesa del demandado, transfiere algún valor a la contraparte. Si el contratante no cumple su promesa, el tribunal lo obligará a restituir lo recibido. En tal caso, el objeto de la indemnización nada tiene que ver con el cumplimiento de la promesa sino con evitar el enriquecimiento injusto del contratante incumplidor a costa del empobrecimiento del accionante. El centro de la preocupación se encuentra en el celebrante que rompe el contrato y no en el accionante. Esta medida es, en general, menor que el interés de la expectativa y que el interés de la confianza. Fuller denomina a ese interés protegido "el interés de la restitución".

En el segundo caso el demandante, confiando en la promesa hecha por su contraparte, cambia su posición. Por ejemplo, el comprador de un inmueble que ha incurrido en gastos en la investigación del título de propiedad del vendedor, o que ha desconsiderado otras oportunidades para celebrar contratos con terceros. En tal circunstancia, el tribunal puede conceder reparación con el objeto de compensar el daño que la confianza depositada en la promesa del demandado le ha producido. El objeto de la indemnización es colocar al accionante en idéntica posición a la que se encontraba antes de que la promesa hubiese sido realizada. Para Fuller, el interés protegido, en tal caso, puede ser denominado "el interés de la confianza".

La doctrina acostumbra distinguir dos tipos de interés de la confianza. El primero consiste en los preparativos adoptados para el cumplimiento y se denomina confianza esencial. El segundo consiste en preparativos para la celebración de contratos colaterales que el sujeto planea ejecutar cuando el contrato en cuestión haya sido cumplido y es llamado confianza incidental. Así, por ejemplo, en el caso de la celebración de un contrato para la construcción de un local comercial, si el dueño de la obra rescinde después de que la empresa constructora 
incurrió en gastos de arquitecto, mano de obra y materiales, esos gastos son considerados del tipo confianza esencial. Por el contrario, si es la empresa la que rescinde después de que el dueño ha realizado dispendios para la compra de bienes perecederos y contratación de personal, esos gastos son del tipo confianza incidental. En ambos casos, el interés de la confianza resultará generalmente menor que el interés de la expectativa porque, en cuanto éste tiene en cuenta tanto el lucro cesante como la confianza, el interés de la confianza no incluye ninguna pérdida en concepto de lucro cesante.

El tercer caso surge cuando precisamente se busca proteger la expectativa creada por la promesa realizada. En tal situación, el objeto perseguido por la indemnización es el de colocar al accionante en idéntica posición a la que este se encontraría si el demandado hubiese cumplido con lo prometido. La acción puede estar dirigida tanto a la obtención de la prestación en sí misma cuanto al valor que ella representa en dinero. A esto Fuller denomina "el interés de la expectativa".

El interés de la expectativa no está basado simplemente en lo que el contratante creía o esperaba al momento de la celebración del contrato, sino en el valor que éste realmente le habría proporcionado de haber sido cumplido. Así, por ejemplo, el valor de la expectativa exageradamente optimista del sujeto que contrata una compañía para cavar pozos de petróleo en su propiedad no será el torrente de petróleo que imaginaba, sino el pozo seco que hubiese resultado si los pozos hubiesen sido efectivamente cavados. (FARNSWORTH, 1990, p. 841).

A modo de ilustración de los tres tipos de interés, podríamos considerar el ejemplo de un contrato de construcción en donde el valor del inmueble a construir en el terreno del dueño de la obra sea de $\$ 100.000$. Si imaginamos que a la empresa constructora le hubiese costado $\$ 90.000$ construirlo y que el dueño del terreno rescinde antes de que el constructor haya incurrido en ningún gasto, en tal caso, el único daño sufrido por el constructor serían los $\$ 10.000$ que habría ganado si el contrato se hubiese cumplido. Este es el interés de su expectativa, ya que ese habría de ser el importe necesario para colocar al constructor 
en la misma posición que tendría si el contrato hubiese sido cumplido. Como el constructor no ha hecho nada en virtud de la confianza generada por el contrato y ningún beneficio fue concedido al dueño del terreno, tanto el interés de la confianza cuanto el interés de la restitución son iguales a cero. Al contrario, si el dueño de la obra rescinde después de que el constructor ha gastado $\$ 60.000$ (de los $\$ 90.000$ que habría costado la construcción total) el interés de la expectativa sería ahora $\$ 70.000$, ya que ésta habría de ser la cantidad necesaria para colocar al constructor en idéntica posición a la que tendría si el contrato hubiese sido cumplido (asumiendo que nada del precio haya sido pagado y que el constructor no está en condiciones de recuperar nada de los $\$ 60.000$ por él invertidos). El interés de la confianza ahora es de $\$ 60.000$, es decir lo que gastó para cumplir. Finalmente, imaginando que el beneficio del dueño del terreno con la obra parcialmente concluida sea de, digamos, $\$ 40.000$, el interés de la restitución sería precisamente esa cuantía.

Fuller sostiene que los tres tipos de interés por él descriptos no poseen idéntico vigor en cuanto a la justicia de su protección. El interés de la restitución, por involucrar la combinación de un empobrecimiento injusto con un enriquecimiento injusto, presenta el caso más sólido desde el punto de vista de la necesidad de su reparación. En efecto, si como afirma Aristóteles, el propósito de la justicia es la manutención de un equilibrio de bienes entre los miembros de la sociedad, el interés de la restitución representa un clamor por la intervención judicial dos veces más potente que el del interés de la confianza ya que $A$, no sólo le causa a $B$ la pérdida de una unidad, sino que él mismo pasa a apropiarse de esa unidad, con lo que resulta que la discrepancia entre $A$ y $B$ no es de sólo una unidad sino de dos. De igual modo, el contratante que de hecho ha confiado en la promesa, aún cuando no haya enriquecido a su contraparte, representa un caso con mayor vigor justificativo de la compensación que aquel contratante que simplemente demanda satisfacción por la frustración de no obtener aquello que se le había prometido.

En la práctica suele haber una superposición entre el interés de la confianza y el de la restitución. En efecto, el cumplimiento del accionante 
representa una forma de confianza que con frecuencia suele beneficiar al demandado y, por otro lado, el requisito en las acciones de restitución de que el accionado debe haber obtenido un beneficio del cumplimiento suele ser bastante flexible.

Una conocida ilustración de la diferencia entre la indemnización protectiva del interés de la expectativa y el de la confianza surge del famoso caso Hawkins $v$ McGee. El actor había sufrido una quemadura en su mano y el demandado, un cirujano plástico interesado en hacer prácticas de injertos de piel, había asumido el compromiso contractual de restaurarla para dejarla en "perfectas condiciones". La operación fue un fracaso y el accionante, no sólo no resultó con su mano en perfectas condiciones como le había sido prometido, sino que terminó con ella en peor estado del que se encontraba antes de la intervención. En el juicio fueron analizadas dos formas en las que la reparación de los daños por incumplimiento contractual podía ser estimada. La primera era deducir del valor que tenía la mano antes de la operación, el valor con el que ésta quedó después de su realización (en la terminología de Fuller, esa estimación protegería el interés de la confianza). La segunda, consistía en descontar del valor de una mano en perfectas condiciones, el valor de la mano después de la operación (esta forma de cálculo protegería el interés de la expectativa. El tribunal concluyó que el accionante tenía derecho a ser colocado en idéntica posición de la que tendría si el contrato hubiese sido cumplido; es decir, se protegió el interés de la expectativa.

Los casos en que el actor no podrá obtener indemnización dirigida a proteger el interés de su expectativa, normalmente serán aquellos en que el accionante no se encuentra en condiciones de probar cual habría sido su posición si el contrato hubiese sido cumplido. McRae v Commonwealth Disposal Commission, un caso australiano, puede servir de ilustración. El actor había comprado del demandado un barco hundido (junto con su contenido) que éste había anunciado en avisos publicitarios como ubicado en un determinado arrecife. El accionante incurrió en gastos considerables para la búsqueda y rescate del navío, pero sucedió que ni el barco ni el arrecife existían. El actor resultó 
victorioso en su demanda por incumplimiento ya que el contrato contenía una cláusula especificando que el navío y el arrecife existían. No obstante, la indemnización por los daños resultantes del incumplimiento no fue estimada en función del valor del barco y su contenido por considerarse que ello sería puramente especulativo. Por el contrario, la compensación concedida fue estimada en función del precio pagado por el navío y los gastos incurridos en la expedición de su búsqueda y rescate. Como se puede apreciar, la indemnización estaba destinada a proteger el interés de la confianza más que el de la expectativa.

Otro conocido leading case, esta vez de origen británico, es el de Anglia Television Ltd. $v$ Reed. El demandante, con la intención de montar la producción para la filmación de una película contrató al demandado como actor para el personaje principal. A los fines de la producción, la compañía incurrió en gastos de dirección, diseño, escenario y contratación de artistas de reparto. El demandado decidió rescindir el contrato pocos días después. En la acción por incumplimiento, el accionante no reclamó los lucros que la producción de la película le habría proporcionado por considerar que su cuantía resultaría de difícil determinación. En cambio, optó por la recuperación de las 2.750 libras que las expensas descriptas le habían significado. La Corte de Apelación confirmó el fallo de primera instancia concediendo dicha cuantía. En este caso se trató igualmente de una indemnización buscando proteger el interés de la confianza de quien no estaba en condiciones de probar el interés de su expectativa.

Naturalmente, la presunción lógica es que, a menos que el accionante imagine perder dinero con su contrato, el interés de la expectativa normalmente le habrá de representar una cuantía mayor que la que le pueda significar la derivada del interés de la confianza. Esto porque aquél presupone el reconocimiento de las ganancias que habrían de resultar del contrato, en tanto que el interés de la confianza habrá de protegerlo simplemente de las pérdidas resultantes. No obstante, la protección del interés de la restitución continúa siendo una vía abierta al accionante aún cuando la del interés de la expectativa no se encuentre imposibilitada. (BURROWS, 1994, p. 250). En ese sentido, puede decirse que algunos principios parecen reglar la relación entre los 
tres tipos de interés en discusión. En primer lugar, se afirma que cuando existe más de un tipo de acción aplicable al caso, la elección cabe al accionante, quien no puede ser forzado por el contratante incumplidor a escoger un tipo en lugar de otro. Esta cuestión, que ya era pacífica, quedó definitivamente consagrada en CCC Films (London) Ltd v Impact Quadrant Films Ltd. en donde el tribunal expresamente estableció que

[...] el actor poseee una elección irrestricta; no es apenas cuando éste evidencia su imposibilidad de probar los lucros cesantes, o que estos serían mínimos, que estará autorizado a encuadrar su demanda como de gastos realizados [...].

El Tribunal también consideró que casos como Cullinane $v$ British Rema Manufacturing Co. Ltd. y Anglia Television Ltd.v Reed constituían autoridad para el principio de que el actor podrá siempre presentar su demanda en la forma de su elección.

Para ilustrar tal situación podríamos imaginar, por ejemplo, un vendedor que ha recibido el precio por adelantado y posteriormente incumple en la entrega de la cosa. El comprador puede elegir entre la devolución del dinero (interés de la restitución) o el valor de los bienes al momento en que debían haber sido entregados (interés de la expectativa). Naturalmente, él habrá de elegir esta última alternativa si la compra resultó ser un buen negocio, o la primera en el caso de haber realizado una negociación desfavorable. Si el vendedor pudiese forzarlo a elegir la restitución, se encontraría en fáciles condiciones de privar al comprador del beneficio de una transacción exitosa.

No obstante, eso no significa que los tribunales habrán de amparar siempre a un contratante que pretenda escapar de los resultados negativos de lo que claramente resultó ser un mal negocio. En el caso mencionado precedentemente de Mc Rae v Commonwealth Disposals Commission, por ejemplo, la indemnización concedida fue de 285 libras, que era el valor pagado por el barco (interés de la restitución) más 3.000 libras que fueron los gastos incurridos en la búsqueda y rescate (interés de la confianza). Sin embargo, la reparación por este último concepto no habría sido por ese valor integral si los demandados hubiesen podido 
probar que, de haber existido el navío, su valor no hubiese excedido las 2.000 libras. En tal caso, obviamente, el accionante habría perdido 1.000 libras, aún cuando el contrato hubiese sido cumplido. En otras palabras, esa pérdida habría sido el resultado de 'un mal negocio' y no el del incumplimiento del accionado. Indemnizar al actor en esas circunstancias habría representado una penalización del demandado y no simplemente la restauración del patrimonio del accionante, por lo que el tribunal seguramente no hubiese legitimado transferir esa pérdida del actor al demandado concediendo la restitución del total de los gastos efectuados. (Hacerlo hubiese significado colocar al actor en mejor posición que la que éste habría tenido si el contrato hubiese sido cumplido) (DOBBS, 1993, p. 774).

Por el contrario, el accionante que demanda en función del interés de la restitución sí puede transferir al demandado una pérdida que haya resultado de un "mal negocio" y no puramente del incumplimiento. Esto ocurre porque, de otra forma, el accionado habría de resultar injustamente enriquecido. La situación se presenta diversa en los casos en que el daño del actor resultante de la confianza excede lo que habría podido ganar con el contrato, ya que esa circunstancia no representa un beneficio patrimonial equivalente de la contraparte y por ello sería injusto hacer pesar sobre éste los referidos daños.

En resumen, en los casos en que el accionado no se encuentre en condiciones de probar que el accionante ha realizado un mal negocio (es decir, que no habría recuperado esas pérdidas aún cuando el contrato hubiese sido cumplido), y el daño resultante de la confianza en el contrato supera al derivado de la expectativa contractual que éste pueda evidenciar, conserva el demandante el derecho de accionar por los daños derivados de la confianza. Por el contrario, si el demandado puede evidenciar que el actor hizo un mal negocio, aquella libre elección deja de existir y éste deberá limitarse a reclamar la cuantía menor de los daños derivados de la expectativa contractual.

En relación a cómo pueden ser combinados los distintos tipos de indemnización, se ha dicho que una acción que procure poner al 
accionante en la misma posición que tendría si el contrato se hubiese cumplido, no puede ser combinada con otra que busque colocarlo en la misma posición que habría tenido si el contrato no hubiese sido celebrado. Sin embargo, los tribunales en numerosas ocasiones han desechado este raciocinio y han concedido indemnizaciones combinando ambos tipos. En Millar's Machinering Co. Ltd. v David Way \& Son, por ejemplo, el actor había comprado (y pagado) una cierta maquinaria que llegó a ser instalada. Posteriormente, el comprador rechazó la maquinaria porque ésta no se ajustaba a las especificaciones establecidas en el contrato. El tribunal hizo lugar a su pedido de devolución del precio (restitución), expensas de instalación (gastos de la confianza) y al lucro cesante (daño de la expectativa).

En realidad, no es que exista una incompatibilidad lógica en la combinación de los diversos tipos de intereses protegidos, sino que el accionante no podrá combinarlos de modo tal a resultar indemnizado más de una vez por el mismo daño. Así, por ejemplo, si un comprador paga por adelantado el precio de un bien que no le es entregado, obviamente no podrá reclamar la devolución del dinero (interés de la restitución) y también el valor que dicho bien habría tenido al momento en que la entrega debió haber siso realizada (interés de la expectativa).

El principio en contra de la dupla indemnización también es aplicable cuando el demandante pretende reparación tanto por el daño derivado de la confianza cuanto por el que surge de la expectativa. En el caso de McRae v Commonwealth Disposals Commission, por ejemplo, si el actor hubiese sido capaz de probar el valor del barco hundido, naturalmente, éste no tendría derecho a ese valor más las 3.285 libras, ya que ésta habría sido la cantidad necesaria para la obtención de aquél (precio del barco más los gastos de búsqueda y rescate).

Australia ofrece un ejemplo similar en George Mitchell (Chesterhall) Ltd v Finney Lock Seeds Ltd. en que un comerciante vendió semillas defectuosas a un agricultor con la lógica consecuencia de una cosecha frustrada. Fue decidido que la reparación debía incluir todos los gastos en que incurrió el accionante en el cultivo de la cosecha arruinada así 
como las ganancias que habría obtenido de una cosecha exitosa si las semillas proporcionadas hubiesen sido de buena calidad. La expresión ganancias, sin embargo, debía ser entendida como el resultado de una cosecha exitosa menos los gastos necesarios para el cultivo ya que éstos habrían sido necesarios aún cuando las semillas no hubiesen sido defectuosas.

Excepcionalmente se podrá tener en cuenta al contratante que no busca la obtención de lucros de la celebración del contrato. Un comerciante, por ejemplo, podría convencionar el envío de determinado producto para exhibición en una feria con el objeto de atraer el interés en sus productos y no el de la realización de ventas inmediatas. Si este propósito es conocido por la contraparte, los gastos realizados en concepto de alquiler de local y otros efectuados con base en la confianza contractual podrán ser recuperados.

\section{Grado de certeza probatoria}

El principio general en materia de cuantificación de daños es que éstos deben ser probados con razonable certeza. Por debajo de ese standard de exigencia o parámetro, los daños, a menudo referidos como especulativos, sólo podrán ser compensados en proporción a las probabilidades de su ocurrencia. Sin embargo, es importante destacar la distinción existente entre la posibilidad de ocurrencia de un determinado daño (que habrá de justificar la proporcionalidad de su reparación de acuerdo con esa probabilidad) y la necesidad de determinación del nexo de causalidad, que ineludiblemente deberá superar el test de la cuestión more probable than not, es decir, que las posibilidades son mayores a un cincuenta por ciento de que el daño se habría evitado si el accionar negligente no hubiese existido...

El leading case en Inglaterra es Hotson v East Berkshire Area Health Authority. El actor había sufrido una caída de la que resultó una lesión en su cadera. El equipo médico del hospital demandado diagnosticó equivocadamente y lo envió a su domicilio. Después de 
cinco días de intensos dolores, el paciente retornó al hospital donde los médicos se percataron del error. El demandante terminó con una discapacidad permanente en la cadera y accionó al nosocomio alegando que, si hubiese sido diagnosticado acertadamente desde el primer momento, la discapacidad habría sido evitada. El juez de primera instancia consideró que, aún cuando el accionante hubiese recibido el tratamiento adecuado, habrían existido $75 \%$ de posibilidades de que la lesión permanente hubiese igualmente subsistido. En consecuencia, concedió al actor $25 \%$ del valor del daño total por haber sido privado de ese porcentaje de las posibilidades de evitar la discapacidad.

La Cámara de los Lores revocó el fallo alegando que si la cuestión central objeto del debate era acerca de la cuantificación del daño, entonces debía hacerse lugar a la demanda del actor, ya que es pacífica la noción de que la reparación del perjuicio debe ser realizada en proporción a las chances de su ocurrencia. Sin embargo, si de lo que en realidad se trataba, era de intentar establecer si el demandado había sido el verdadero causante del daño producido, es decir, si la cuestión era determinar la causa y no apenas la cuantificación del daño, entonces la demanda debía ser rechazada, ya que el accionante no había conseguido probar, conforme al balance de probabilidades, que la lesión experimentada había sido causa de la negligencia hospitalaria y no de la propia caída.

\section{Los límites a la obligación de reparar}

El common law desarrolló un sistema de reglas para tentar poner ciertos límites, de modo a evitar resultados indeseables en aquellos casos en que conceder indemnización por todos los daños sufridos por el contratante, pueda ser considerado excesivo o inapropiado.

La doctrina acostumbra referirse a un caso de principios del siglo XVII y que aparece mencionado en British Columbia Saw-Mill Co. Ltd $v$ Nettleship. Un hombre que se dirigía a su casamiento con una importante heredera, tuvo que detenerse en el camino para cambiar las 
herraduras de su caballo. Para ello, contrató un herrero quien realizó un trabajo tan mal hecho que el caballo resultó con lastimaduras en sus patas. El infeliz caballero no pudo llegar a tiempo a su propia boda y la dama terminó casándose con otro. El hombre entró con una acción y el herrero fue responsabilizado por la pérdida del matrimonio. En British Columbia Saw-Mill Co. Ltd v Nettleship se hace referencia precisamente a ese caso, al que se le atribuye la condición de "absurdo", para señalar la necesidad de establecer reglas que limiten la obligación de reparar en los casos de incumplimiento contractual.

\section{La previsibilidad del daño como límite. La regla de Hadley v Baxendale}

Hasta 1845 prácticamente no existían reglas referidas a la indemnización por daños. Se trataba de un ámbito librado enteramente al criterio de los jurados, sistema este que comenzó a evidenciarse inapropiado para la nueva economía que comenzaba a desarrollarse en Inglaterra. En ese año Hadley v Baxendale fue decidido, consolidándose rápidamente como el leading case más importante en materia de límites a la obligación de reparar daños contractuales. Ese fallo, que reflejaba al mismo tiempo los cambios que se estaban produciendo tanto en la economía como en el sistema judicial inglés, y que puede parecer expresión de una política de protección empresarial, continua siendo, más de 150 años después, "una estrella sólida en el firmamento jurisprudencial.” (GILMORE, 1974, p. 92).

El accionante poseía un molino de granos que había dejado de funcionar después de que su eje central se quebrara. Hadley contrató al demandado para que transportase por vía marítima el eje roto hasta una compañía de ingenieros para que le fabricasen uno nuevo usando el antiguo como modelo. El accionado injustificadamente demoró el transporte por varios días y como resultado el molino debió permanecer cerrado por bastante más tiempo del que habría sido necesario si el envío hubiese sido realizado en tiempo y forma. 
El jurado concedió indemnización por el lucro cesante. En apelación, el fallo fue revocado. La Corte de Exchequer (Corte de Apelación) estableció dos reglas que continúan siendo válidas hasta el presente. Primero: el damnificado tiene derecho a ser indemnizado por aquellos daños

que puedan ser razonablemente considerados como resultado natural, es decir -de acuerdo con el curso natural de las cosas-, como consecuencia del incumplimiento.' Segundo: en el caso en que circunstancias especiales hubiesen sido comunicadas al demandado, la compensación también es debida en relación a daños que 'razonablemente pudieran haber sido contemplados por ambos contratantes, al momento de la celebración del contrato, como un probable resultado del incumplimiento.

El Barón Alderson, en su famoso voto, afirmó que la única circunstancia que había sido comunicada por el accionante al accionado al momento de la celebración del contrato había sido que ellos tenían un molino y que el eje de ese molino se había roto. Según el magistrado, no hubo información de ninguna circunstancia especial como la de que el molino se encontraba paralizado y que sensibles pérdidas habrían de producirse en el caso de una eventual demora en el transporte del eje damnificado y, por tanto, ningún lucro cesante podría ser concedido con base en la regla de la "contemplación" (previsibilidad). El raciocinio continuaba sosteniendo que

obviamente, en la gran mayoría de los casos de molinos que envían piezas dañadas a terceros para ser transportadas, el molino no se encontraría paralizado pues sus propietarios acostumbran tener piezas de repuesto para esas ocasiones, o están en condiciones de conseguir otro, o hasta podría no estar funcionando porque otras piezas estaban igualmente con defecto, en cuyo caso, la demora en el transporte sería indiferente para la continuidad de las operaciones del molino.

En consecuencia, la reparación por los lucros cesantes no era cabible de acuerdo con la regla del curso ordinario de las cosas. 
En resumen, la existencia de especiales circunstancias que alejasen el caso del curso ordinario de las cosas debía haber sido informada al accionado al momento de la contratación. Como todo el conocimiento que éste poseía era el de que el eje iba a ser llevado a Greenwich para su reparación, el demandante carecía de derecho a ser compensado por lo que dejó de ganar durante el período en que el molino permaneció cerrado por la demora en el transporte.

Se podría afirmar que el conocimiento poseído puede ser considerado de dos clases: uno presumido y otro real. Todo contratante, como hombre razonable, se presume que conoce el "curso normal de los acontecimientos" y, en consecuencia, el daño que pueda resultar del incumplimiento de acuerdo con ese curso normal de las cosas. Este es el contenido de la primera parte de la regla en Hadley $v$ Baxendale. Pero a este conocimiento que el contratante incumplidor se presume que posee (independientemente de que lo tenga, o no) debe agregarse el conocimiento particular, que de hecho posea, de especiales circunstancias (fuera del curso ordinario de las cosas), en donde el incumplimiento habría de provocar un daño mayor.

Al establecer el requisito de la contemplación para posibilitar la compensación del daño indirecto (consequential damages), el Tribunal impuso una significativa nueva limitación en las indemnizaciones por incumplimiento que los jurados podían conceder. El resultado fue que las restricciones indemnizatorias en el ámbito contractual se tornaron más severas que las existentes en materia extra-contractual.

En Estados Unidos, el requisito de la contemplación, al menos durante un tiempo, tuvo una interpretación aún más restrictiva. En efecto, algunos tribunales pasaron a afirmar que un contratante no era responsable del daño "indirecto" (consequential damages) a menos que, al momento de la celebración del contrato, hubiese tácitamente aceptado asumir el riesgo de tal responsabilidad. Es decir, que la simple comunicación a la otra parte de circunstancias que tornarían previsible el daño resultante en caso de incumplimiento, no sería suficiente. Oliver Wendell Holmes, que fuera miembro de la Suprema Corte de Estados 
Unidos por treinta años y que constituye sin duda el mas influyente magistrado en la historia de la jurisprudencia americana, fue uno de los ardientes defensores de esta interpretación.

En rigor, la teoría del acuerdo tácito estaba basada en la dudosa suposición de que la indemnización por incumplimiento deriva de la promesa, expresa o implícita, de los contratantes de compensar los daños en caso de incumplimiento, más que en la idea de la existencia de una obligación secundaria impuesta por la ley como consecuencia del incumplimiento. No obstante, esa interpretación restrictiva extrema ha sido dejada de lado ya hace tiempo. De hecho, la significación de las expresiones previsibilidad y comunicación se han revelado susceptibles de fácil manipulación. En ese sentido, el caso conocido como The Heron II, decidido por la Cámara de los Lores en Inglaterra, puede servir como ilustración. Un navío de carga había sido fletado para transportar un cargamento de azúcar de Constanza a Basra. En el curso del viaje, el barco efectuó lo que se consideró como un injustificable desvío, con el resultado de que el mismo arribó a destino nueve días más tarde de lo que debía. En ese lapso, el precio del azúcar en Basra se había derrumbado. Los contratantes demandaron al propietario del barco por los daños resultantes, es decir, la diferencia entre el precio por el que se podría haber vendido si hubiese arribado a tiempo y el precio por el que efectivamente se vendió.

El demandado sabía que estaba transportando azúcar para alguien que pretendía venderla en Basra. Ignoraba si éste habría de venderla de manera inmediata, o si habría de ser almacenada para su posterior venta más avanzado el año. Es más, el hecho de que el precio de mercado haya colapsado en esos nueve días era totalmente fortuito, podría, del mismo modo, tanto haber subido como mantenerse estable.

La Cámara de los Lores consideró que el accionado tenía derecho a ser indemnizado en conformidad con los principios establecidos en Hadley $v$ Baxendale. Lord Reid, en el voto principal declaró que el propietario del navío tenía suficiente información como para percibir que el daño 'no era improbable.' Sin duda, que de la 'tácita aceptación de 
los riesgos' al 'daño no improbable' la distancia es tan grande como el océano que separa a ambos tribunales.

En relación a lo que se considera 'previsibilidad', si bien el concepto es sumamente elástico, algunas precisiones pueden ser enumeradas. En primer lugar, aquella debe ser analizada al momento de la celebración del contrato, no pudiendo ser afectada por eventos posteriores. En segundo lugar, lo que debe ser previsible es sólo el daño resultante de existir incumplimiento. No se requiere que el incumplimiento en si mismo, o el modo particular en que el daño se produjo, hayan sido previsibles. Tercero: la previsibilidad que interesa es sólo la que se refiere al contratante incumplidor. Esta interpretación, al presente, es pacífica, aún cuando el Barón Alderson se haya referido a la contemplación de "ambos contratantes". Cuarto: la previsibilidad tiene un carácter objetivo, es decir, el contratante que celebra un contrato asume el riesgo no sólo por las consecuencias que previó, sino también por aquellas que razonablemente debía haber previsto. Lo que el accionado debía deducir de las circunstancias por él conocidas es generalmente juzgado de acuerdo al parámetro del hombre razonable. Por otro lado, para que el contratante incumplidor pueda ser responsabilizado, no es necesario que de hecho él se haya preguntado que daños podrían derivar de su incumplimiento. Como acertadamente se ha señalado, los contratantes al momento de la celebración, generalmente contemplan el cumplimiento de sus obligaciones y no lo contrario. En consecuencia, es suficiente que, si hubiese considerado la cuestión, él habría, como hombre razonable, concluido que el daño de referencia habría podido resultar. Quinto: el daño sólo requiere ser previsible como hecho probable y no como resultado necesario o cierto derivado del incumplimiento.

Hadley $v$ Baxendale encuentra su versión más moderna en Victoria Laundry (Windsor) Ltd $v$ Newman Industries Ltd . ratificando sus principios. La accionante, una empresa de tintorería, contrató la compra de un termo tanque. Los accionados sabían que su contraparte necesitaba el termo tanque para uso inmediato en su negocio. No obstante, en incumplimiento de su obligación, lo entregaron con una demora de cinco meses. Los demandantes accionaron por el lucro 
cesante, incluyendo las inusuales ganancias que habrían resultado de un contrato que aquellos estarían en condiciones de celebrar con el gobierno si hubiesen tenido el termo tanque.

La Corte de Apelación, aplicando Hadley v Baxendale, sostuvo que la compensación debía ser calculada en función de los lucros cesantes normales, pero no los extraordinarios. Éstos constituían daños vinculados muy remotamente ${ }^{3}$ con la causa, ya que no surgían naturalmente y no podían haberse encontrado en contemplación de los accionados, pues éstos nada sabían en relación a los contratos con el gobierno.

En general, se acepta de modo incontestable que el accionado no debe responder por aquellos daños que, si bien era previsible que ocurriesen en el curso ordinario de las cosas, de hecho el accionante no los sufrió, ni tampoco por aquellas pérdidas cuya vinculación causal con el incumplimiento son consideradas muy distantes. Sin embargo, esta regla es excepcionalmente dejada de lado cuando el accionante sufre un daño de esa naturaleza, siendo que era previsible para el accionado la posibilidad de que resultara otro daño, de menor cuantía.

El leading case es un antiguo caso del año 1868: Cory $v$ Thames Ironworks Co. en el cual los accionados habían incumplido su obligación de entregar el casco de un barco en el tiempo debido. El actor, un comerciante de carbón, pretendía usar el casco de un modo inusual e ignorado por los demandados. Éstos habían asumido que el casco habría de ser empleado para el uso habitual de la época, es decir, para almacenar carbón. Si la finalidad hubiera sido efectivamente esa, la pérdida habría sido de 420 libras, pero los accionantes planeaban emplear el casco en un revolucionario método para transferir el carbón de barcos cargueros a las barcazas y, con eso, dejaron de ganar 4.000 libras. Fue decidido que, si bien el daño resultante del uso peculiar era

\footnotetext{
3 El common law emplea la expresión too remote que es el daño que el contratante no pudo haber razonablemente contemplado (previsto) como una seria posibilidad de ocurrir si hubiese pensado en el incumplimiento al momento de la celebración del contrato.
} 
causalmente remoto, las ganancias menores que habrían resultado de la aplicación habitual del casco era indemnizable. Esto, aún cuando, de hecho, el actor no hubiese sufrido tal daño por no pretender utilizar el casco para almacenamiento.

A la frecuente crítica de que el autor termina siendo indemnizado por un daño que no sufrió, se acostumbra responder que el principio debe ser interpretado como la compensación parcial del accionante por las ganancias especiales que dejó de obtener, en el valor equivalente a los lucros normales que habría perdido. (BURROWS, 1994, p. 57).

Más dudoso sería si el daño sufrido fuese de un tipo substancialmente diferente del que habría sufrido según el curso normal de las cosas. Imagínese, por ejemplo, un comerciante que vende alimento para vacas que contiene una alta dosis tóxica a un ganadero quien, ignorando tal circunstancia, decide comer él mismo el alimento por encontrarse trabajando en un novedoso experimento nutricional y fallece.¿Podrían sus herederos accionar al comerciante por la muerte de una vaca? (TREITEL, 2001, p. 903)

Otro caso de enorme repercusión en materia de límites a la responsabilidad por incumplimiento contractual es Parsons $v$ Uttley Ingham. Los accionados habían vendido al actor unas tolvas de carga para almacenar comida para cerdos. Los receptáculos carecían de ventilación adecuada de modo que los alimentos se echaron a perder y numerosos animales murieron como consecuencia de una rara enfermedad intestinal. El actor accionó reclamando los daños sufridos.

Los tres miembros de la Corte de Apelación coincidieron en afirmar que esos daños eran previsibles (not too remote). No obstante, el voto de Lord Denning, apartándose de la mayoría, presenta significativos aspectos para el análisis. De acuerdo con el ilustre magistrado, existen dos tipos de tests para avaliar la previsibilidad del daño contractual (es decir determinar si puede o no ser considerado too remote), dependiendo de la naturaleza del referido daño. En relación al lucro cesante, un test más riguroso debe ser aplicado: "el contratante incumplidor es responsable únicamente por aquellas consecuencias que, al momento 
de la celebración del contrato, debía razonablemente haber contemplado como una seria posibilidad o peligro real."

Como Hadley $v$ Baxendale, Victoria Laundry (Windsor) Ltd $v$ Newman Industries Ltd. y The Heron II, todos ellos, estaban referidos a lucros cesantes, sostenía Lord Denning que se aplicó el test más estricto. Al contrario, en relación al daño físico, el magistrado consideraba que el test menos riguroso del daño extra-contractual debía ser aplicado. De acuerdo con ello y en conformidad con lo que había sido establecido en el emblemático caso del Wagon Mound (el leading case en materia de daño extracontractual) Denning entendía que el contratante incumplidor es responsable por todo daño que debía razonablemente haber previsto al momento de la celebración del contrato como una posible consecuencia, aún cuando ésta haya sido una ligera posibilidad.

Como este caso estaba referido a daño físico (la pérdida de los animales), Lord Denning aplicó el referido test para enfatizar que era el tipo, más que la extensión del daño, o la forma en que este ocurre lo que era importante. Es así que arriba a la conclusión de que la muerte de los animales debía ser indemnizada, lo cual, en su opinión, no habría ocurrido si el test más rígido, aplicable en el ámbito contractual, hubiese sido utilizado.

Como se puede observar, desde esa perspectiva, la tradicional discusión acerca de la identidad o no de la extensión de la responsabilidad (contractual y extra-contractual) pasa a ocupar un lugar secundario, siendo que el elemento determinativo pasa a ser ahora la naturaleza del daño: lucro cesante o daño físico. Lord Denning dejó en claro su opinión acerca de que, cuando un sujeto es responsable contractualmente por daño físico frente a una persona y extra-contractualmente frente a otra, no debería existir ninguna distinción en relación al parámetro a ser aplicado para determinar el grado de previsibilidad del daño exigible. El grado de previsibilidad (test of remoteness) es y debería ser el mismo. Lo que no surge con nitidez del análisis del referido magistrado es qué parámetro debería ser aplicado para el caso de lucro cesante por daño extra-contractual. En otras palabras, Denning utiliza dos indagaciones 
diferentes para establecer la existencia o no de obligación indemnizatoria del daño contractual, pero no aclara si en el ámbito extra-contractual debería igualmente ser aplicado un duplo test investigatorio.

Los otros dos miembros que conformaron la mayoría del Tribunal no pensaban que la distinción establecida por Denning pudiese encontrar apoyo en los precedentes. Para éstos, la indagación en ambos casos (lucro cesante o daño físico) debía ser la establecida en The Heron II. Más particularmente, lo que debía ser contemplado como una seria posibilidad era el tipo de consecuencia y no necesariamente la consecuencia específica que derivó del incumplimiento. Por tanto, como era razonablemente previsible al momento de la celebración del contrato, que un incumplimiento en la entrega de las tolvas de un modo adecuado para el almacenamiento de alimento para cerdos representaría una seria posibilidad de que éstos contrajesen alguna enfermedad, y como una enfermedad podía ser considerada dentro del mismo tipo de daño que el de la muerte, era irrelevante que la extensión de esa enfermedad (es decir la muerte de los animales) no hubiese sido contemplada como una seria posibilidad. Por esa razón, la mayoría arribaba a la conclusión de que la pérdida de los animales no podía ser considerado un daño remoto y, por tanto, no sujeto a reparación.

Naturalmente, el voto de la mayoría despierta algunos interrogantes en relación a cómo distinguir los distintos tipos de daños. Se podría argumentar, por ejemplo, que si la enfermedad y muerte de los animales eran considerados como haciendo parte del mismo tipo de daños y que simplemente diferían en intensidad, el fallo en sí mismo resultaba entonces irreconciliable con Victoria Laundry (Windsor) Ltd $v$ Newman Industries Ltd. ya que, sin duda, sería posible también en éste sostener que el daño en cuestión era el lucro cesante y que los lucros excepcionales serían simplemente una expresión más extensa o intensa del mismo tipo de daño.

En resumen, podría decirse que existen tres puntos de vista principales acerca de la indagación a ser realizada (remoteness test) para determinar la reparabilidad o no del daño contractual. Primero: el 
que prevaleció en The Heron II, es decir, que el análisis es diferente en materia contractual y que en este ámbito, el parámetro de exigencia a ser alcanzado en cuanto al grado de previsibilidad debido para que exista responsabilidad es más alto que en materia extra-contractual. Las razones que justificarían la distinción, de acuerdo con Lord Reid, residen en que en el ámbito contractual, si una parte desea protegerse contra un riesgo de daño que aparecería inusual a los ojos del otro contratante, puede llamar la atención de su contraparte antes de la celebración del contrato. En materia extra-contractual, por el contrario, no existe la posibilidad de que la víctima tenga una protección equivalente y, por tanto, el causante del daño no puede quejarse por tener que compensar un daño inusual, aunque previsible, resultante de su negligencia.

Segundo: la posición mayoritaria en Parsons v Uttley Ingham que, básicamente ratifica lo decidido en The Heron II, pero con el énfasis puesto en el tipo de daño más que en su extensión o intensidad. Esta posición, presumiblemente está basada en la idea de que pretender la contemplación o previsibilidad, tanto del tipo cuanto de la extensión o intensidad del daño para considerar su reparación, sería tornar la cuestión demasiado favorable para el accionado.

Tercero: la opinión de Lord Denning en el sentido de que la indagación es la misma tanto en materia contractual como extracontractual en relación al daño físico, pero en relación a lucros cesantes en el ámbito contractual, es aplicable el test más riguroso establecido en The Heron II.

Pero, ¿cuál seria la razón que justificaría la existencia de un diferente nivel de exigencia para el daño físico que para el lucro cesante? La primera sería de orden histórico: tradicionalmente el common law ha considerado que dejar de obtener una ganancia es menos grave, más especulativo y más incierto que el daño físico y, por tanto, los tribunales tendrían menor predisposición para amparar un accionante que alega lucros cesantes que quien invoca daños físicos. En consecuencia, sería necesario un mayor grado de exigencia para determinar la reparabilidad de aquel. Dicho de otro modo, el lucro cesante estaría siempre en el 
ámbito de lo hipotético, en cuanto que el daño físico, así como los gastos realizados, hasta cierto punto, harían parte de los hechos pasados (y por tanto de determinación precisa).

La segunda razón sería que, en general, se podría decir que, si bien es realista pensar en la posibilidad de un contratante informar al otro acerca de la eventualidad de daño por lucros cesantes, sería fantasioso pensar en idéntica posibilidad en relación a daño físico. Esto porque los celebrantes, que acostumbran considerar la posibilidad de pérdidas económicas como consecuencia del incumplimiento, jamás lo hacen en relación a los daños físicos.

\section{La ejecución forzosa}

Contrariamente a lo que ocurre en los sistemas romanistas, en el common law, la condenación forzosa al cumplimiento del contrato es excepcional. La regla es la indemnización del valor equivalente. Apenas cuando esta última, por alguna razón es considerada inadecuada, estará habilitada aquella medida.

Históricamente, la satisfacción del acreedor por este medio no era concedida por los tribunales del common law sino por las Cortes de Equidad (Courts of Chancery) que eran tribunales con poder discrecionario y que para decidir, tenían en cuenta, no sólo la conducta del demandante sino también la del accionado para determinar si éste era merecedor de la asistencia de la Corte.

Los tribunales del common law no desarrollaron el cumplimiento forzoso porque se aceptaba el principio de que el dinero podía siempre representar el equivalente de algo que se había prometido.

Como los tribunales de equidad complementaban, más que suplantaban a los del common law, la concesión de compensación en especie ha sido siempre muy cautelosa y limitada. En general, era aplicada cuando el tribunal podía 'prestar una justicia más completa y perfecta'. 
La regla, al presente, continúa siendo la de que la condenación forzosa a cumplir lo prometido no será concedida si la prestación dineraria equivalente representa una compensación adecuada para el accionante. El principal modo de compensación en el common law es una satisfacción substitutiva; es decir, en lugar de ordenar cumplir lo prometido, se ordena pagar el valor de aquello que se prometió. Al revés de lo que ocurre con la compensación monetaria, que es aplicable frente a cualquier incumplimiento, la reparación en especie sólo lo será cuando el accionante consiga superar los numerosos obstáculos existentes a su aplicación. En resumen, un demandante en el common law, sólo obtendrá una sentencia condenatoria ordenando el cumplimiento del contrato si consigue demostrar que la reparación id quod interest se presenta como inadecuada.

\section{La diferencia en valor o el costo para reparar}

Como la condenación in natura es excepcional, una de las dificultades que se presenta al tratar de colocar al accionante 'en la misma posición en que estaría si el contrato se hubiese cumplido' es que existen dos bases para su determinación: la diferencia en valor y el costo para reparar (difference in value and cost of cure).

Un caso que evidencia la enorme diferencia económica que puede existir entre una y otra vía indemnizatoria es Peevyhouse v Garland Coal \& Mining Co. Willie y Lucille Peevyhouse eran propietarios de un campo de 120 acres en Oklahoma, donde vivían, sembraban y criaban ganado. En 1954 rentaron la mitad de esa extensión de tierra a los accionados para que éstos pudieran realizar trabajos de minería, con la condición de que, al finalizar, efectuaran nivelaciones en el terreno de modo tal que permaneciera en el mismo estado en que se encontraba antes del inicio del contrato. Finalizado el contrato, la empresa abandonó las tierras sin haber realizado los mencionados trabajos de nivelación, por lo que los Peevyhouse accionaron por la suma de U\$S 25.000, que era el valor estimado para la realización de aquellos. 
Los accionados reconocieron el incumplimiento, pero manifestaron que la compensación a los actores debía limitarse a la disminución del valor del inmueble como consecuencia del incumplimiento (establecido como siendo U\$S 5.000 en Primera Instancia). Ambas partes apelaron a la Corte Suprema de Oklahoma que confirmó el fallo, pero redujo la cifra compensatoria a U\$S 300. La resolución (en fallo dividido 5 a 4) sostuvo que, cuando el incumplimiento es meramente accesorio de la obligación principal y el beneficio económico derivado del cumplimiento total resulta significativamente desproporcional al costo del cumplimiento in natura, la compensación debe limitarse a la disminución del valor del inmueble provocada por el incumplimiento.

El voto mayoritario destacaba que U\$S 5.000 representaba un valor superior al que habría tenido el terreno si los trabajos hubiesen sido realizados. Asimismo refería la existencia de una ley estadual que establecía que "ningún contratante puede obtener en concepto de daños por incumplimiento una cantidad superior a la que habría obtenido si el contrato hubiese sido cumplido en su totalidad por ambas partes."

La opinión disidente argumentaba que todos los costos y dificultades para el cumplimiento de esa obligación podrían haber sido previstos al momento de la celebración del contrato y que los demandados reconocieron que los accionantes habían insistido en la inclusión de la referida cláusula, sin la cual, no habrían celebrado el contrato.

En los contratos de compraventa en que el objeto no es de la calidad convencionada, los daños en general, son determinados con base en la diferencia de valor. Ya en los contratos de construcción, por ejemplo, la indemnización en principio es establecida en función del costo para realizar los trabajos como deberían haber sido hechos, o de completarlos en concordancia con lo que fue convencionado.

La situación puede ser diferente en los casos en que el costo para reparar se encuentre en significativa desproporción con el beneficio que la reparación pueda representar para el accionante. Tal sería el caso, por ejemplo, cuando algunos elementos en discordancia con lo pactado 
han sido instalados en una determinada construcción que debería ser substancialmente demolida para realizar la substitución, o cuando la ejecución de un determinado trabajo no traería aparejada ninguna ventaja económica para el actor. En tales casos, la diferencia en valor (si es que existiese) sería la base normal para la determinación de los daños.

El leading case es Jacobs \& Youngs $v$ Kent. Las partes habían celebrado un contrato de construcción de una vivienda. El trabajo fue concluido y el propietario se mudó y comenzó a vivir en ella. Un año después advirtió que parte de las cañerías instaladas no eran las que habían sido establecidas en el pliego de especificaciones. El propietario se negó a pagar un saldo adeudado al constructor exigiendo la substitución de las mencionadas cañerías. En apelación, la Cámara, con el voto del Juez Cardozo, determinó que, como la falta era de carácter trivial y no había sido dolosa, el actor tenía derecho a la percepción de lo adeudado, menos la diferencia en valor de la propiedad (si es que tal existiese) por no contar con las cañerías de la marca especificada.

En general, los casos en que se ordena el cumplimiento específico están vinculados a objetos que se presentan como de difícil disposición en el mercado. Es decir que como una substitución satisfactoria de ese objeto no se encuentra al alcance del acreedor, el remedio es considerado inadecuado. El ejemplo más obvio es el de las obras de arte, pero el más habitual se presenta en las ventas inmobiliarias en donde la singularidad del objeto comprometido adquiere particular relevancia, sin que eso signifique que los tribunales habrán de limitarse a ordenar el cumplimiento forzoso de la obligación apenas cuando el comprador le atribuya a la propiedad un valor subjetivo superior al valor de mercado. Del mismo modo, resulta indiferente la motivación interna del contratante, es decir si adquirió para revender, para inversión a largo plazo, o para vivienda propia.

Si bien aparece justificada la razón en el caso de la inversión a largo plazo por las dificultades existentes para determinar cual habría de ser su lucro, no se visualiza la lógica frente a la eventualidad de una 
reventa inmediata, particularmente si esta operación ya fue concretada. A lo que parece, simplemente en materia de venta inmobiliaria, el hábito procesal de la condenación al cumplimiento específico opera quase automáticamente. Los orígenes históricos sin duda ejercen su influencia aún hasta el presente. En efecto, en la Inglaterra medieval, se consolidó la doctrina de que cada parcela de tierra y cada interés en ella eran únicos. El principio era absolutamente coherente con una sociedad en donde el lugar que una persona ocupaba en ella, a menudo derivaba de la naturaleza y calidad de la tierra que poseía. Por esa razón, una indemnización que tuviese en cuenta apenas la substitución de su valor en dinero era considerada inadecuada.

Para tentar ayudar en la comprensión de algunas dificultades existentes en materia de indemnización por daños, la doctrina del common law ha adaptado un concepto poco familiar en el ámbito jurídico, la más-valía del consumidor. El referido concepto está basado en la idea de que el valor subjetivo de un objeto para un individuo puede, en ciertas ocasiones, divergir de su valor representado por su precio de mercado.

El ejemplo clásico es el de un sujeto que, mentalmente y por anticipación, decide hasta cuánto estaría dispuesto a pagar por un objeto en un remate (valor máximo). Si, posteriormente, él consigue adquirirlo por menos, la diferencia es su más-valía del consumidor. En otras palabras, si él es capaz de comprar por \$100, lo que estaba dispuesto a pagar $\$ 150$, el ahorro de $\$ 50$ representa su más-valía del consumidor. La medida del valor de aquel objeto, para él, está dada más por su disposición a pagar que por el precio (o valor) de mercado.

A diferencia del comerciante, que busca un lucro, y por tanto está interesado en el 'valor de cambio', el adquirente particular compra las cosas para usarlas y, por tanto, está interesado en el 'valor de uso'.

Esta noción es útil para explicar, por ejemplo, porqué, una persona, en la eventualidad de un incumplimiento de contrato, difícilmente será colocada en la "misma posición en que se encontraría si el contrato hubiese sido cumplido" si la condenación por los daños sufridos 
reflejasen apenas la diferencia en el valor de mercado del objeto de que se trate.

\section{Conclusión}

A pesar de algunos cuestionamientos por parte de sectores minoritarios, el common law no parece dispuesto a rever su posición históricamente consolidada en relación a cual debe ser el modo más adecuad, conforme a los principios de justicia, para proteger a los contratantes frente a los incumplimientos obligacionales. La reparación por equivalencia parece, a los ojos de las cortes, practicantes y críticos del derecho en aquel sistema, satisfacer más adecuadamente que el cumplimiento forzoso de la obligación prometida y, en consecuencia, la reparación in natura, continuará siendo un remedio excepcional, aplicable exclusivamente cuando la substitución por el equivalente monetario no se muestre apropiada.

\section{Referências}

BURROWS, Andrew. Remedies for torts and breach of contract. London: Butterworths, 2017.

DOBBS, Dan. Law of remedies. Eagon: West Publishing, 1993.

ENNECERUS, Ludwig. Tratado de Derecho Civil. Barcelona: Bosch, 1954. t. II.

FARNSWORTH, Allan. Contracts. Boston: Little, Brown and Company, 2004.

GILMORE, Grant. The death of the contract. Columbus: Ohio State University Press, 1974

HOLMES, Oliver Wendell. The path of the law. Boston: 10 Harvard Law Review, 1897.

TREITEL, Günter. The law of contract. London: Sweet \& Maxwell, 2011. 


\section{JURISPRUDENCIA CITADA.}

Anglia Television Ltd. v Reed. 3 All E.R. 690 (C.A.1971)

British Columbia Saw-Mill Co. Ltd v Nettleship 3 L.R. C.P. 499 (1868) CCC Films (London) Ltd v Impact Quadrant Films Ltd. (1985) Q.B. 16. Cory v Thames Ironworks Co. L.R. 3 Q. B. 181 (1868) Cullinane v British Rema Manufacturing Co.Ltd. [1953] 2 All ER 1257 George Mitchell (Chesterhall) Ltd v Finney Lock Seeds Ltd. [1983] 2 AC 803

Hadley v Baxendale. [1854] EWHC J70.

Hawkins v McGee. N.H. 114, 146A. 641 (1929)

Hotson v East Berkshire Area H. A. [1987] 2 All ER 909.

Jacobs \& Youngs $v$ Kent. 230 N.Y. 239, 129 N.E. 889 (N.Y. 1921)

McRae v Commonwealth Disposal Commission (1951) 84 CLR 377.

Millar's Machinering Co. Ltd. v David Way \& Son. (1935) 40 Com.Cas. 204.

Parsons v Uttley Ingham. [1978] QB 791.

Peevyhouse v Garland Coal \& Mining Co. 382 P.2d 109 (Okl.1962).

Robinson v Harman (1848) 1 Ex. Rep. 850.

The Heron II. [1967] UKHL 4.

Victoria Laundry (Windsor) Ltd v Newman Industries Ltd. [1949] 2 KB 528.

Wilson v Northampton and Banbury Junction Railway Co. (1874) L.R. 9 Ch.App. 279, 284.

Recebido em: 22/10/2016

Aprovado em: 14/11/2016 